\title{
Assessment of the Vapor Phase Catalytic Ammonia Removal (VPCAR) Technology at the MSFC ECLS Test Facility
}

\author{
Kristin Tomes, David Long, and Layne Carter \\ NASA Marshall Space Flight Center \\ Michael Flynn \\ NASA Ames Research Center
}

\begin{abstract}
The Vapor Phase Catalytic Ammonia Removal (VPCAR) technology has been previously discussed as a viable option for the Exploration Water Recovery System. This technology integrates a phase change process with catalytic oxidation in the vapor phase to produce potable water from exploration mission wastewaters. A developmental prototype VPCAR was designed, built and tested under funding provided by a National Research Announcement (NRA) project. The core technology, a Wiped Film Rotating Device (WFRD) was provided by Water Reuse Technologies under the NRA, whereas Hamilton Sundstrand Space Systems International performed the hardware integration and acceptance test of the system. Personnel at the Ames Research Center performed initial systems test of the VPCAR using ersatz solutions. To assess the viability of this hardware for Exploration Life Support (ELS) applications, the hardware has been modified and tested at the MSFC ECLS Test Facility. This paper summarizes the hardware modifications and test results and provides an assessment of this technology for the ELS application.
\end{abstract}

\section{INTRODUCTION}

The Vapor Phase Catalytic Ammonia Removal (VPCAR) unit was funded through Ames Research Center (ARC) as a candidate technology for the Exploration Water Recovery System. The core of the technology is the Wiped Film Rotating Disc (WFRD), designed and built by Water Reuse Technology. Hamilton Sundstrand Space Systems International integrated the WFRD into a functioning system, adding the required pumps, compressors, valving, instrumentation, and plumbing to support hardware operation. Test of the unit was performed at ARC with ersatz solutions to establish initial performance metrics (1). However, to fully assess the viability of this technology for an ELS mission, long duration testing with actual wastewaters was needed. The capability to perform this type of integrated test is available at the Marshall Space Flight Center (MSFC) Environmental Control and Life Support (ECLS) Test Facility, where engineers have conducted development and qualification tests of the ISS Water Recovery System for almost 20 years. At the ECLS Test Facility, test volunteers support the generation of all wastewaters anticipated from ELS missions, including urine and crew latent from respiration/perspiration and hygiene activities. The VPCAR was delivered to MSFC in September 2005 and was tested from January 2006 to March 2007.

\section{VPCAR TESTING}

The primary test objectives for the VPCAR were to assess the long term performance of the VPCAR when processing pretreated urine and humidity condensate at a $98 \%$ water recovery rate. This recovery rate is higher than the rate of $94 \%$ currently established for other phase change processes (including Vapor Compression Distillation technology to be used on International Space Station). The basis for the additional water recovery is through the wiped film process, in which a wiper blade continually sweeps the surface of the evaporator disc in part to prevent the precipitation of solids that would inhibit the evaporation/condensation process. The wastewater used in the test is defined in Table 1. Urine was collected from volunteers and treated with $250 \mathrm{ml}$ of flush water (deionized water), $5 \mathrm{~g}$ of oxone, $2.3 \mathrm{~g}$ of sulfuric acid, and $1 \mathrm{~g}$ of potassium benzoate per liter of urine in order to both chemically and microbiologically stabilize it. Humidity condensate was generated by test volunteers that performed exercise and hygiene activities in an enclosed chamber at the MSFC ECLS Test Facility. Water quantities used for hygiene activities were 
consistent with that used on the International Space Station. The condensate was collected with a condensing heat exchanger and delivered to the VPCAR waste tank for processing with the pretreated urine. A condensate supplement ersatz was added to the condensate to add contaminants that are not present in the test facility condensate at concentrations expected in an ELS mission.

Table 1. VPCAR Wastewater Definition

\begin{tabular}{|l|l|}
\hline Wastewater & \multicolumn{1}{|c|}{ Water Quantity } \\
\hline $\begin{array}{l}\text { Humidity } \\
\text { Condensate }\end{array}$ & $8.91 \mathrm{~kg} /$ day $(19.8 \mathrm{lb} /$ day $)$ \\
\hline Handwash & 11 per day \\
\hline $\begin{array}{l}\text { Full Body } \\
\text { Wash }\end{array}$ & 6 per day \\
\hline Wet Shave & 3 shaves/day \\
\hline Oral Hygiene & 11 toothbrush/day \\
\hline $\begin{array}{l}\text { Pretreated } \\
\text { Urine }\end{array}$ & $10.48 \mathrm{~kg} /$ day $(23.1 \mathrm{lb} /$ day $)$ \\
\hline $\begin{array}{l}\text { Condensate } \\
\text { Supplement }\end{array}$ & $1.43 \mathrm{~kg} /$ day $(3.15 \mathrm{lb} /$ day) \\
\hline
\end{tabular}

\section{VPCAR Description}

A simplified schematic of the VPCAR process is provided in Figure 1. The wastewater is fed to the WFRD evaporators at a pressure of 40-100 torr and a temperature of $50-60^{\circ} \mathrm{C}$. The WFRD is composed of 4 evaporators operating in parallel, each with a wiper blade that serves to maintain a thin liquid film on the evaporator surface for optimum thermal efficiency while also preventing precipitation on the evaporator surface. The vapor phase generated under these conditions is removed by the compressor and sent to the catalytic reactor at an elevated temperature and pressure. Nonvolatile species remain in the waste brine, which is circulated through the evaporators with periodic addition of feed and removal of brine to maintain the water recovery rate. The compressed vapor is mixed with gaseous oxygen and passed through an oxidation reactor to react the volatile organics. The vapor phase is then fed to two condensers, one between each set of evaporators. The compressor insures that the condenser is operated at a higher temperature than the evaporator. Because the evaporators and condensers are separated by only a thin metal disk, the latent heat from the condensing water transfers itself to the evaporator to support the evaporation of the incoming feed water, thus recycling the thermal energy. The product water is pumped out of the condenser while the excess oxygen and non-condensable gases are removed by the vacuum pump.

In the VPCAR delivered to MSFC, a reduction reactor was also employed for further treatment of the vapor phase. However, this reactor was removed at MSFC since the targeted contaminants can be more readily removed by the habitat's Trace Contaminant Control System that will be present on any manned mission using a Water Recovery System. A vacuum pump is used to remove the non-condensables (vented to the environment) and maintain the system at vacuum conditions. Water vapor in the vacuum line is condensed and removed prior to the vacuum pump.

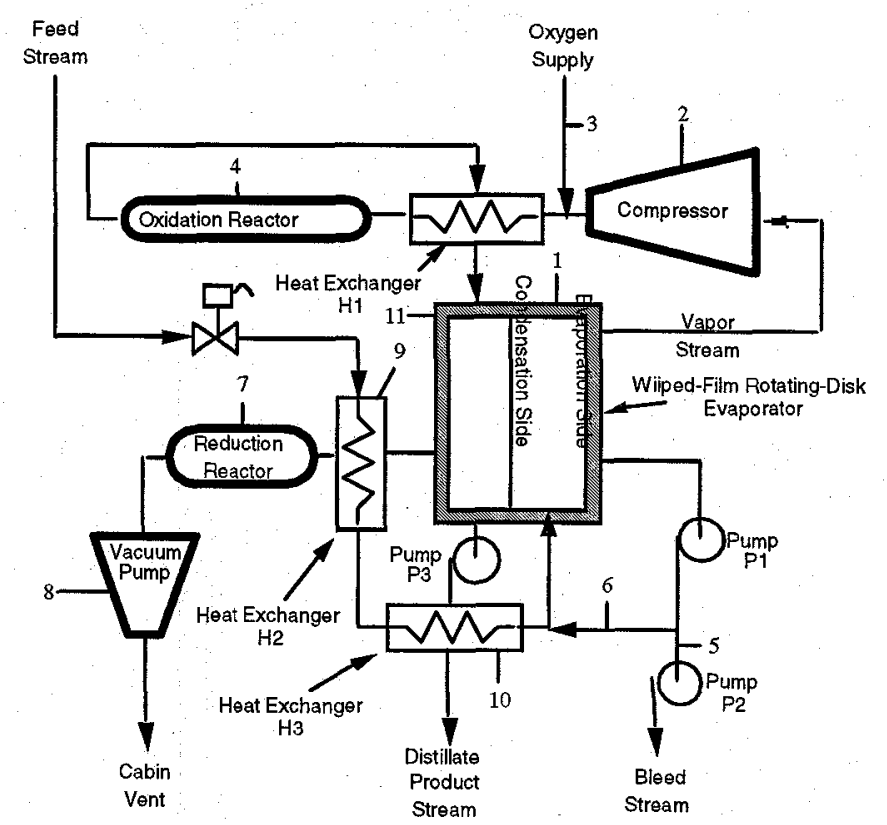

Figure 1. VPCAR Schematic

\section{VPCAR Operation}

The objective of the test was to operate the VPCAR continuously with the system in standby only during wastewater transfers. All facility tanks were on scales that read into the data stream to record changes in mass for all fluids entering and leaving the system in order to maintain an accurate mass balance.

Initially the VPCAR was operated without allowing any brine to leave the system in order to reach $98 \%$ recovery. Based on volume calculations of the brine loop, it was determined that approximately $45 \mathrm{~kg}$ (100 lbs) of feed must be processed to achieve this recovery rate. Once the brine loop was concentrated, brine was metered out of the loop while feed water was added to maintain a $98 \%$ recovery rate. This was done based on a software algorithm that allowed $0.023 \mathrm{~kg}(0.05 \mathrm{lbs})$ of brine to leave the system for every $1.13 \mathrm{~kg}(2.5 \mathrm{lbs})$ of feed added to the loop according to scale weights.

Oxygen was injected into the system at a rate of 500 $\mathrm{ml} / \mathrm{min}, 2068$ torr (40 psig), which corresponds to a mass flow rate of $1.06 \mathrm{~kg} / \mathrm{hr}$, to feed the oxidation reactor. System requirements were to run at a rate of $1 \mathrm{~L} / \mathrm{min}$, 1551-2585 torr (30-50 psig), which corresponds to 2.12 $\mathrm{kg} / \mathrm{hr}$. However, during checkout testing, this higher flow rate caused the compressor power to increase due to the vacuum system not being able to remove the excess oxygen as quickly as it should. Water quality was monitored to ensure that it was not affected by the lower oxygen flow rate. 
Samples were taken of the condensate, pretreated urine, combined waste, brine, and product water to assess VPCAR performance. Sample analysis ensured that product water quality was acceptable and helped to verify the recovery rate based on the percent solids in the brine loop.

\section{RESULTS}

Three separate attempts were made to operate the VPCAR for an extended duration. For each test run, the brine loop was first concentrated to a solids concentration corresponding to $98 \%$ recovery. The system is designed to produce $5.8 \mathrm{~kg} / \mathrm{hr}(13 \mathrm{lb} / \mathrm{r})$, but in each run the production rate initially averaged only 1.4$2.7 \mathrm{~kg} / \mathrm{hr}(3-6 \mathrm{lb} / \mathrm{hr})$. Furthermore, the production rate of product water would decrease even lower to approximately $0.23 \mathrm{~kg} / \mathrm{hr}(0.5 \mathrm{lb} / \mathrm{hr})$ once the brine loop was concentrated.

\section{Test Run 1}

The first attempt to run at $98 \%$ recovery was a 7 day test. During the first day of testing, feed was taken in to be processed but no water was produced. However, the system began producing water during test day 2 . Concentration was reached during this day and the brine ejection logic was initiated. Near the end of day 2, the production rate began to decrease and the system pressures and temperatures dropped. Testing was allowed to continue through day 7 , though the production rate and system pressures/temperatures never returned to their previous operating values.

Based on the results of this test, two system modifications were made. First, the product water pump (Pump B) was not functioning correctly, thus the pump gears were replaced. Because this pump could not effectively move water from the condenser to the product tank, a majority of the water went out the vacuum line to a cold trap that was then pumped to the product tank. In order to quantify how much product was leaving the system through the vacuum line, a three way solenoid valve was used to direct any water collected in the cold trap to go to a separate collection container. Also, to address concerns that the loss in production was due to precipitation on the evaporator surface, a citric acid flush was performed to help remove any scaling inside the evaporators that might have been affecting heat transfer from the condenser to the evaporator.

\section{Test Run 2}

The second test run lasted for 2 days. Again, the production rate, temperatures, and pressures were at acceptable levels for the first day and a half of testing. The production rate then began to decrease and a significant rubbing noise from inside the WFRD became evident. The citric acid flush was repeated to again attempt to remove any scaling that might have formed inside the evaporators.

Subsequent attempts to operate the VPCAR were not successful. The rubbing noise inside the WFRD became worse, and there were times when the rotating sumps locked up and would not rotate without manually adjusting them. Finally, the motor shaft driving the WFRD broke as shown in Figure 2.

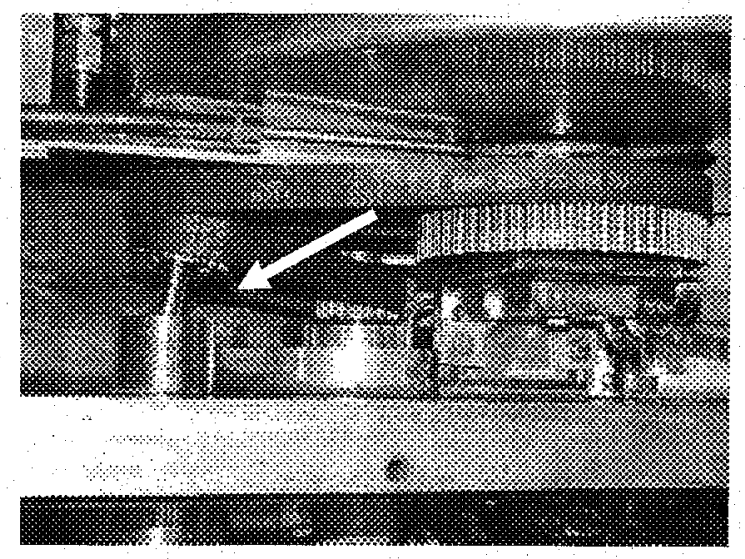

Figure 2. Broken WFRD Motor Shaft

A new motor shaft was manufactured that addressed some of the design issues of the shaft as received. At the point of diameter change on the shaft, a full radius was added to provide strength that would prevent fatigue. During this time, the evaporators were disassembled to investigate the reason for the low production rate. There were several significant findings during disassembly. Figure 3 shows each evaporator labeled to make discussion of these findings easier to understand.

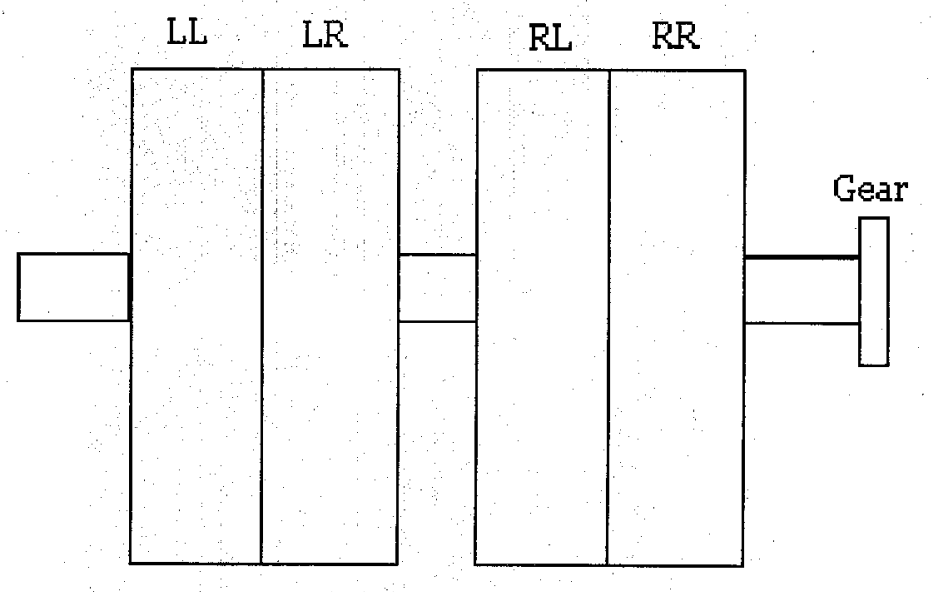

Figure 3. WFRD Evaporator Labels

In each of the four evaporators, crystalline brine was found inside the evaporator covers with the worst being in the LL evaporator. Figure 4 shows the precipitation in each evaporator. Samples were taken for analysis with the results provided in Table 2 . The data was generated 
by dissolving $3.24 \mathrm{~g}$ of the solid sample in $20 \mathrm{ml}$ of citric acid solution. Chloride, Nitrite and Bromide were not detectable due to the interference of the various organic acids present. However, if these contaminants had been present, they would have been in very low quantities.

Table 2 - Analysis of Crystalline Brine

\begin{tabular}{|l|l|l|l|}
\hline Cations & $\mathrm{ppm}$ & Anions & $\mathrm{ppm}$ \\
\hline Sodium & 22.4 & Chloride & ${ }^{*}$ \\
\hline Ammonium & 7.2 & Nitrite & ${ }^{*}$ \\
\hline Potassium & 86.6 & Phosphate & $<0.5$ \\
\hline Magnesium & 0.6 & Sulfate & 581 \\
\hline Calcium & 86.7 & Bromide & ${ }^{*}$ \\
\hline
\end{tabular}

* not detectable due to interference with organic acids.
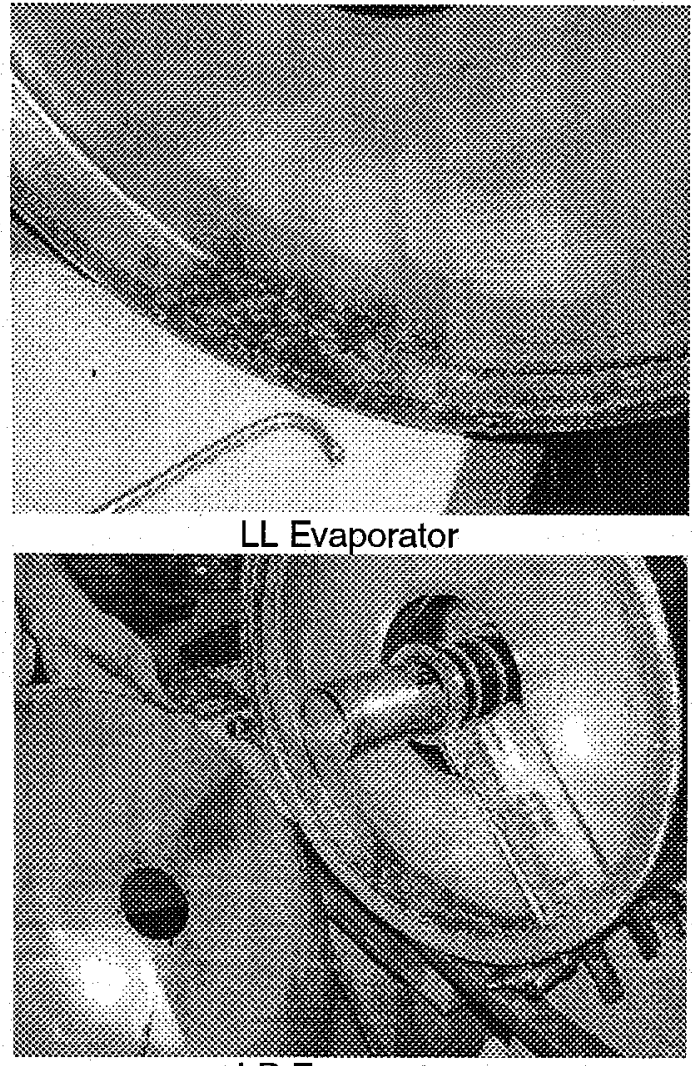

LR Evaporator

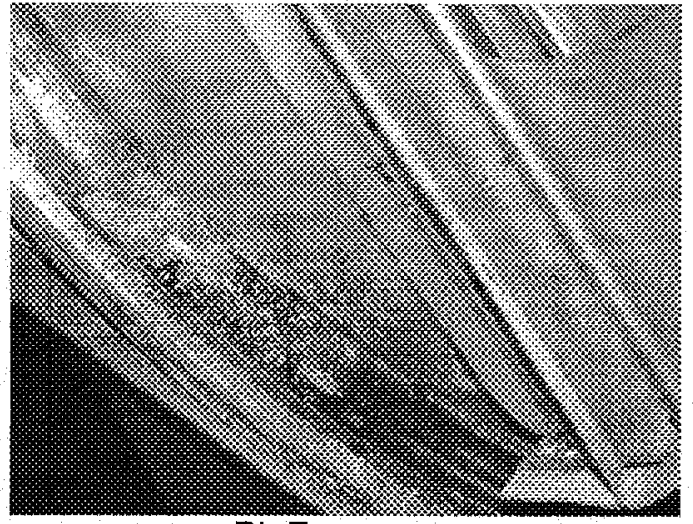

RL Evaporator

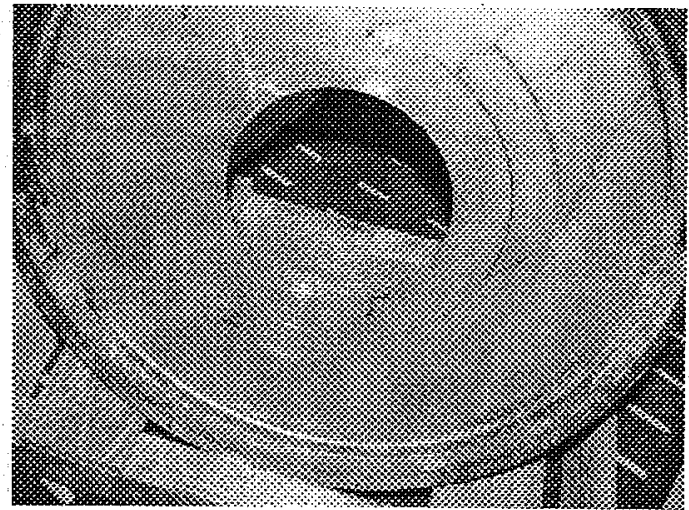

RR Evaporator

Figure 4. Crystal Growth inside Evaporators during Test Run 2

The brine pickup tube in both the LL and LR evaporators was broken with the $L L$ tube bent significantly. Most likely, precipitation had built up until it interfered with the pickup tube, resulting in the evaporators locking up and also the damage to the pickupt tubes. Figure 5 shows these in comparison to one of the other pickup tubes that was intact.
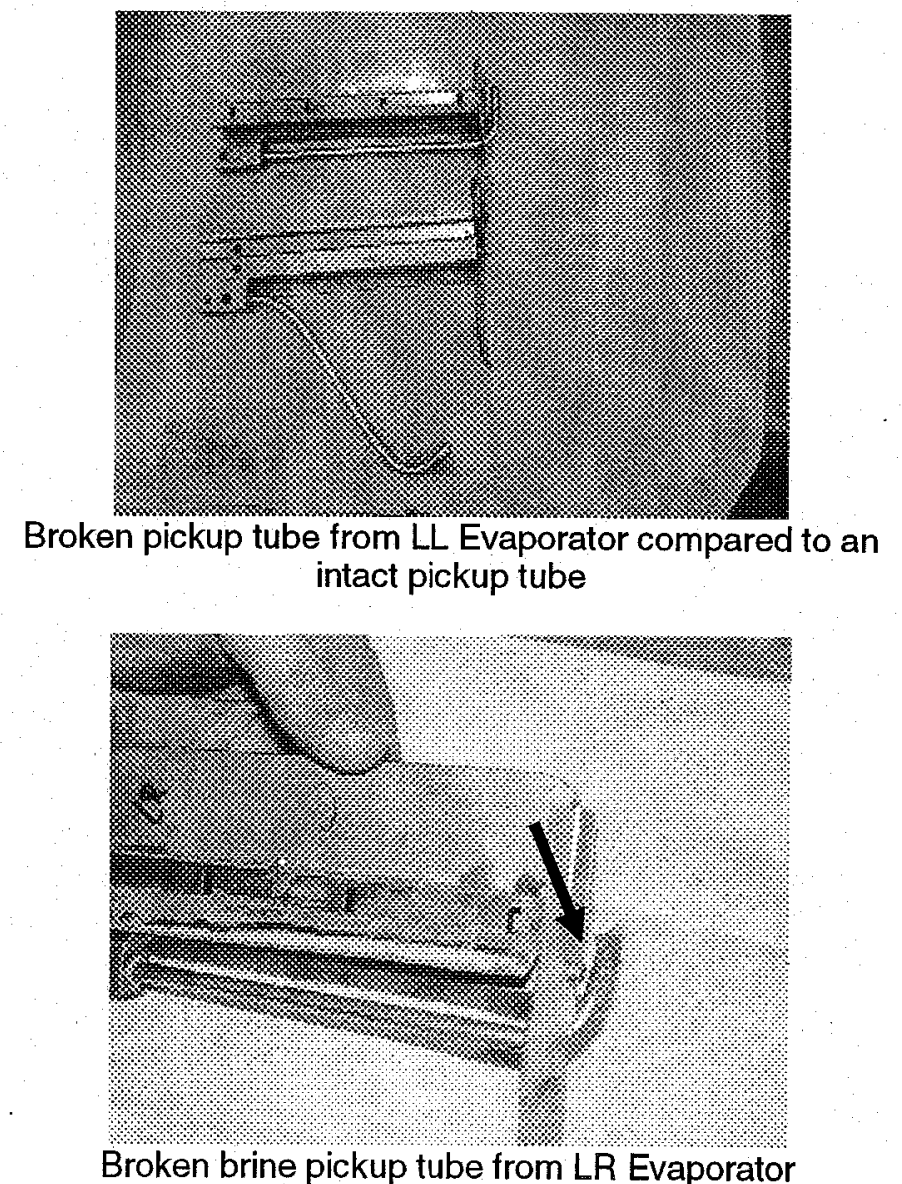

Figure 5. Broken Brine Pickup Tubes during Test Run 2

In addition to these issues there was also a significant amount of oil inside the RR gravity cover from the broken motor shaft. The evaporators were cleaned to remove 
the precipitation and oil, the pickup tubes were repaired, system tubing contaminated with the oil was replaced, and the hardware was reassembled. Furthermore, the tubing that feeds the WFRD was leaking significantly into the 1-G sump. This caused the level sensor in the sump to frequently require the sump to be pumped out (back to the feed). Two failed tubes were repaired and another reinforced. Finally, the system was operated with deionized water to flush out any residual oil left in the plumbing.

\section{Test Run 3}

The final attempt at a long duration run at $98 \%$ recovery lasted 14 days. The production rate was initially at an acceptable level and the system reached concentration during day 5 (due to the amount of time the system was operated on a daily basis before continuous run was initiated) at which time the brine ejection logic was enabled. At this point, the brine loop was at $25.5 \%$ solids. The last brine sample taken was on test day 11 and the percent solids had increased to $30.8 \%$ even though the logic was set to maintain $98 \%$ recovery.

Production rate began to drop near the end of test day 7 and continued to decrease for the remainder of the test.

As with the previous two tests, pressures and temperatures decreased and did not return to their initial operational values. Figure 7 shows plots of T2, T12, T9, and T10 during a 5 hour operational period of good production rate as compared to a 5 hour operational period of low production rate.

T2, which is the temperature of the feed before entering the WFRD, varied a small amount between good and low production times. This is due to the fact that facility software was set to control the feed temperature to $65.6 \mathrm{C}(150 \mathrm{~F})$. T12, however, is the temperature inside the WFRD that dictates when the solenoid valve will open to allow flow to the product tank. As can be seen, T12 dropped approximately $1.5 \mathrm{C}$ when the production rate decreased.

T9 is the temperature of the oxidation reactor effluent stream before entering the Water Reuse Technology Heat Exchanger (WRT HX). During normal production this temperature cycled around $176.7 \mathrm{C}$ (350 F). However, once production rate began to drop; T9 dropped to just under $65.6 \mathrm{C}(150 \mathrm{~F})$. T10 is the temperature of the oxidation reactor effluent as it leaves the WRT HX and which is used to control the coolant flow through the WRT HX. Facility software is set to control this temperature to $104.4 \mathrm{C}(220 \mathrm{~F})$ which is done during normal operation. Once production rate dropped, T10 never exceeded $82.2 \mathrm{C}(180 \mathrm{~F}$ ) thus not requiring coolant to enter the system. 

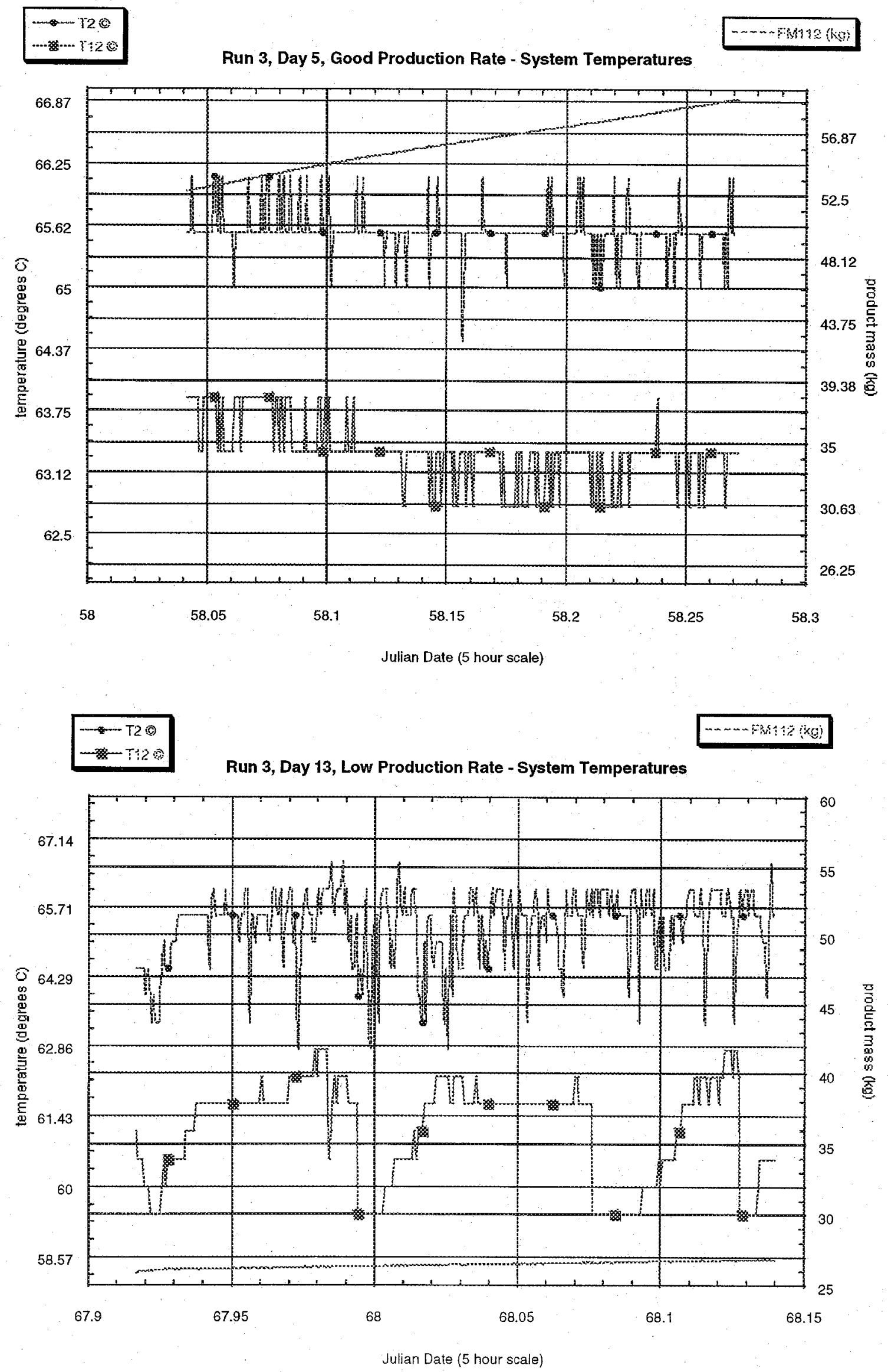
Run 3, Day 5, Good Production Rate - Coolant and Reactor Temperatures

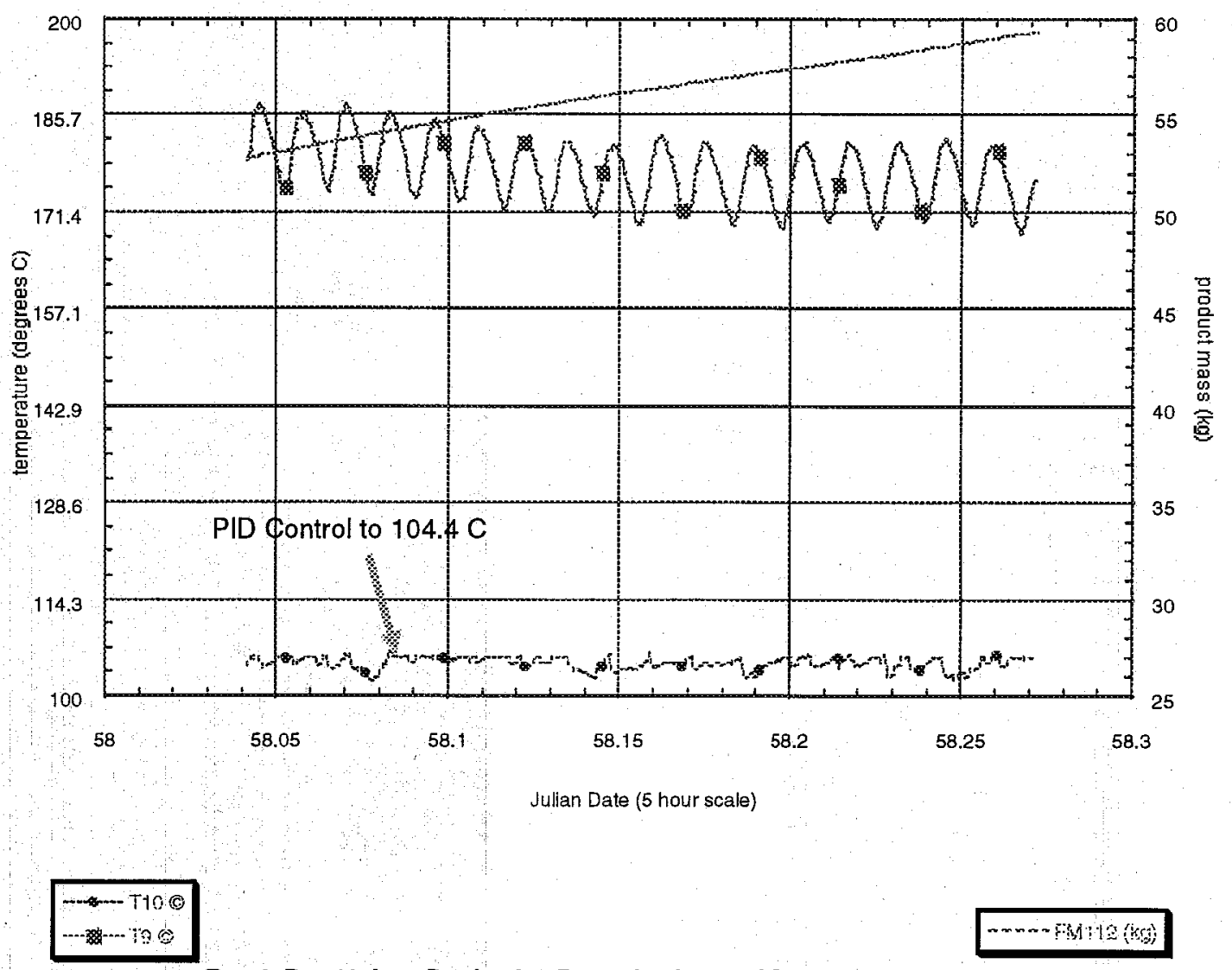

Run 3, Day 13, Low Production Rate - Coolant and Reactor Temperatures

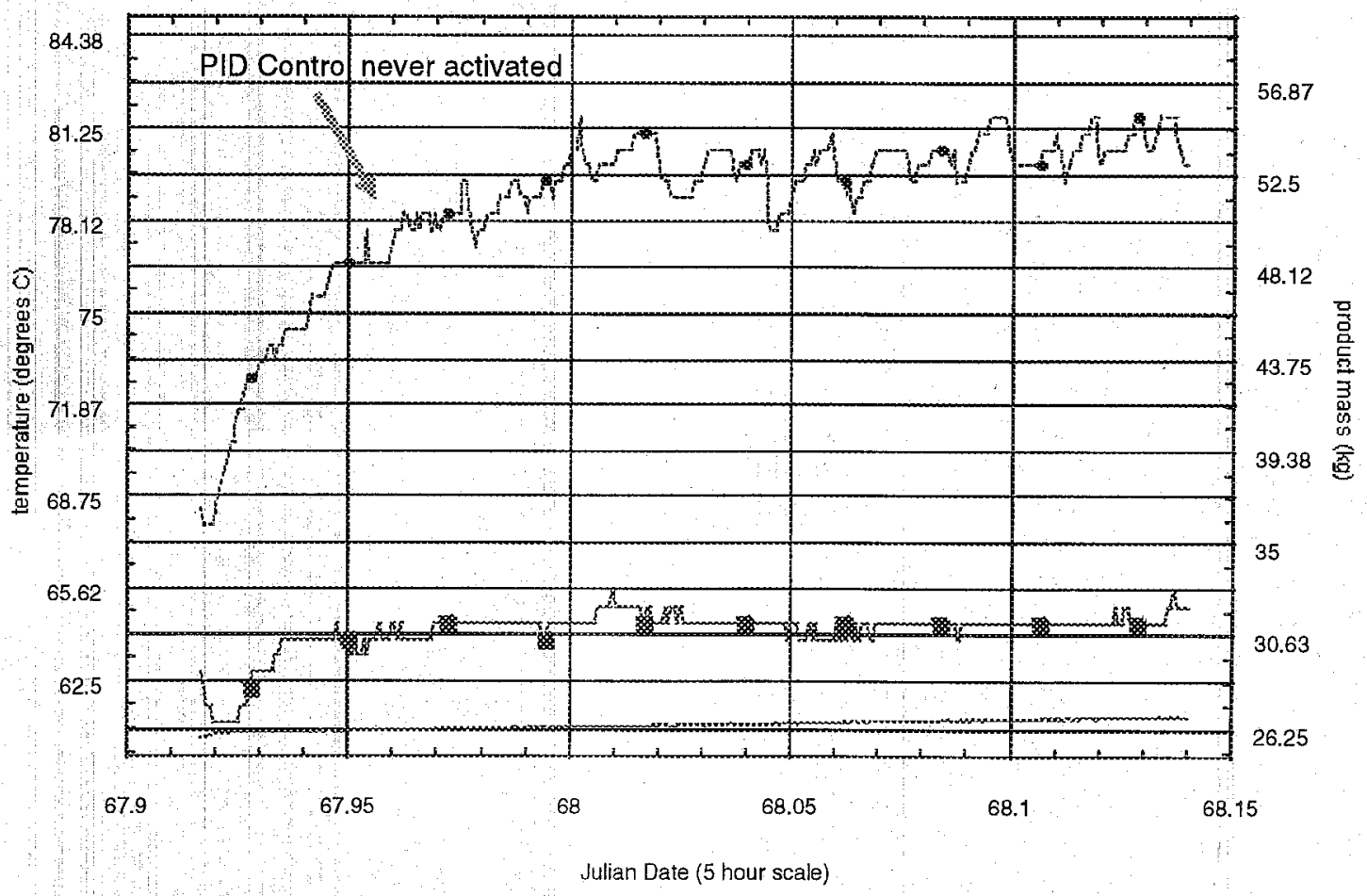

Figure 7. Comparison of System Temperatures during Good and Low Production Periods 
During this test run, the rubbing noise inside the WFRD continued to get worse. Several shaft position adjustments were made in an attempt to alleviate the rubbing, but never succeeded. In addition, an imbalance in the WFRD shaft was observed. This imbalance occurred anytime the brine was fed to the evaporators. When the evaporators were operated without the brine feed, there was not a rotational issue. Finally, while observing the imbalance, the motor shaft that drives the WFRD broke in the same location as noted in Figure 2. Following this failure, no further testing of the VPCAR was pursued.

Before the rotating sumps were removed from the system, brine samples were taken from each evaporator, the brine tank, and the gravity sump for comparison. Table 2 shows the sample data. These results show that the concentration level inside the evaporators is higher than that of the brine tank as seen by the \% solids value. When taking system samples, a sample port just upstream of the brine tank is used. This data shows that the solids concentration level inside the system is actually higher than the concentration level in the brine removed from the system.

Table 3. Final Brine Sample Data

\begin{tabular}{|c|c|c|c|}
\hline $\begin{array}{c}\text { Sample } \\
\text { Location }\end{array}$ & $\begin{array}{c}\% \\
\text { Solids }\end{array}$ & $\mathbf{p H}$ & $\begin{array}{c}\text { Conductivity } \\
(\boldsymbol{\mu S} / \mathbf{c m})\end{array}$ \\
\hline Brine Tank & 22.4 & 3.2 & 105,000 \\
\hline Gravity Sump & 28.5 & 4.3 & 117,000 \\
\hline LL Evaporator & 34.0 & 4.3 & 117,000 \\
\hline LR Evaporator & 39.0 & 4.3 & 117,000 \\
\hline RL Evaporator & 36.5 & 4.3 & 117,600 \\
\hline RR Evaporator & 39.0 & 4.3 & 118,200 \\
\hline
\end{tabular}

The evaporators were disassembled to look for any source of rotational imbalance. A significant amount of precipitation was seen on the rotating sumps and shaft that seemed to be "baked on" brine. This was not evident during the previous disassembly. Most likely, the repair performed on the feed tubes eliminated a significant source of liquid into the 1-G sump. As a result, the limited brine that escaped the evaporator had more opportunity to "bake" onto the surfaces. As with the previous disassembly, precipitation had occurred in the evaporators. However, the precipitation was not solid crystalline as before. It is likely that the precipitation observed during the disassembly following Test Run 2 was initiated in previous testing at Ames Research Center, and only increased during tests at MSFC until the interference with the pickup tubes occurred. Since the disassembly following Test Run 3 occurred within a week of stopping the test, there was not enough time for the precipitation to crystallize. During this disassembly, test engineers also determined that the WFRD dry film sleeve had come lose. This sleeve allows the sumps to rotate around the shaft smoothly, and was most likely the source of the rubbing sound. The sleeve is similar in appearance to Vespel. See Figure 8 for disassembly photographs.

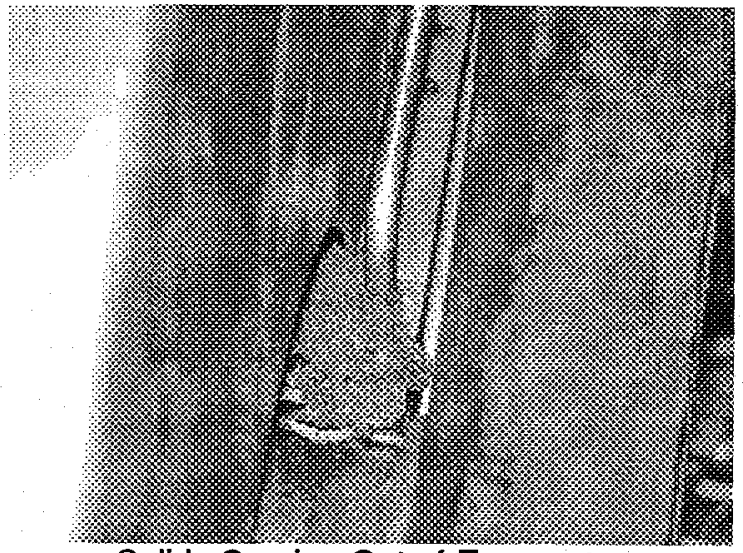

Solids Coming Out of Evaporator

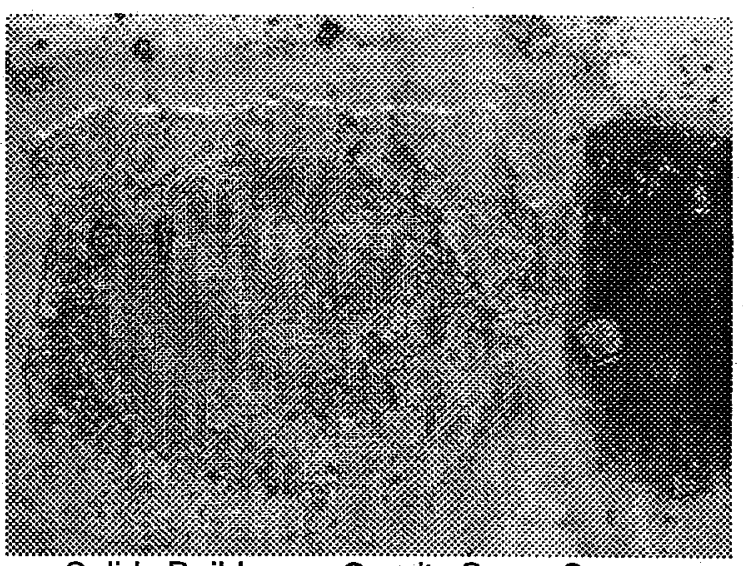

Solids Buildup on Gravity Sump Screen
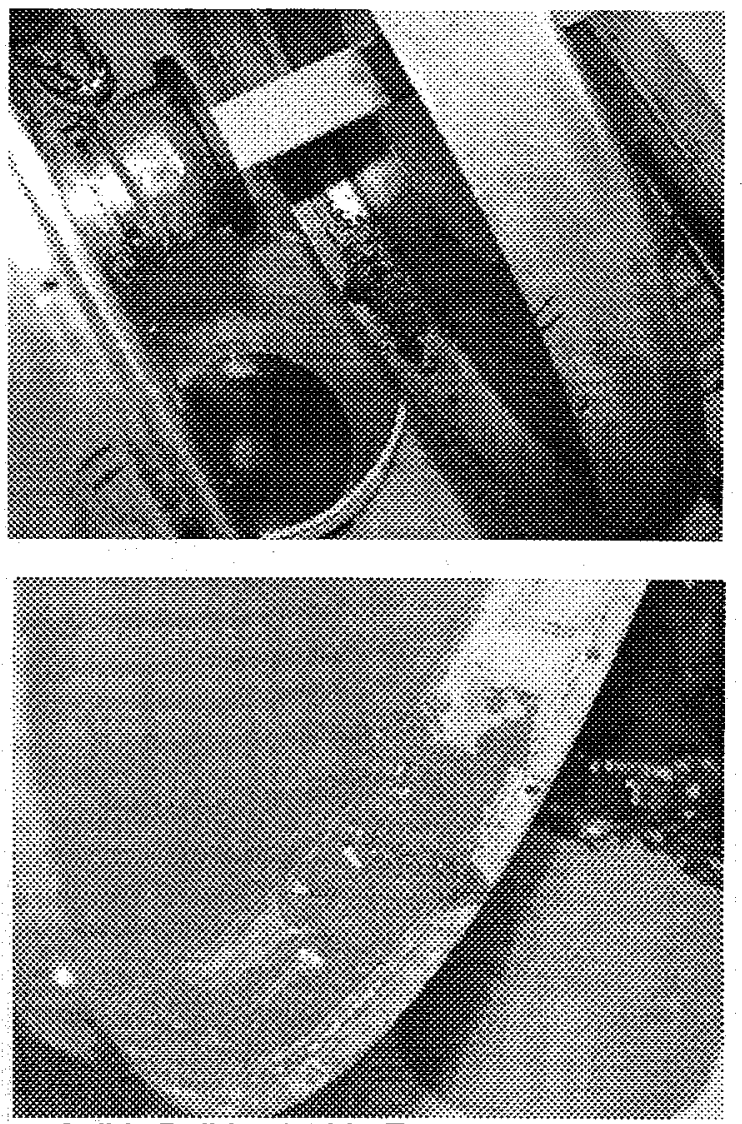

Solids Buildup inside Evaporator Covers 


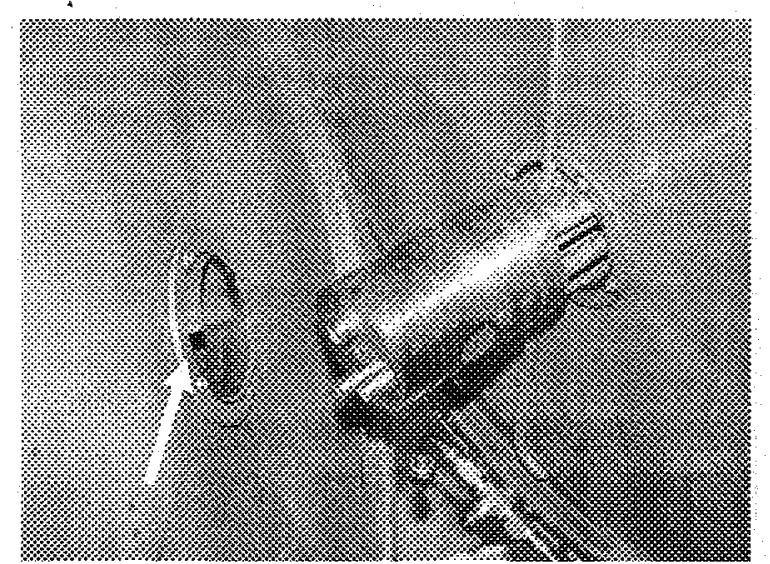

Broken Dry Film Bearing Sleeve

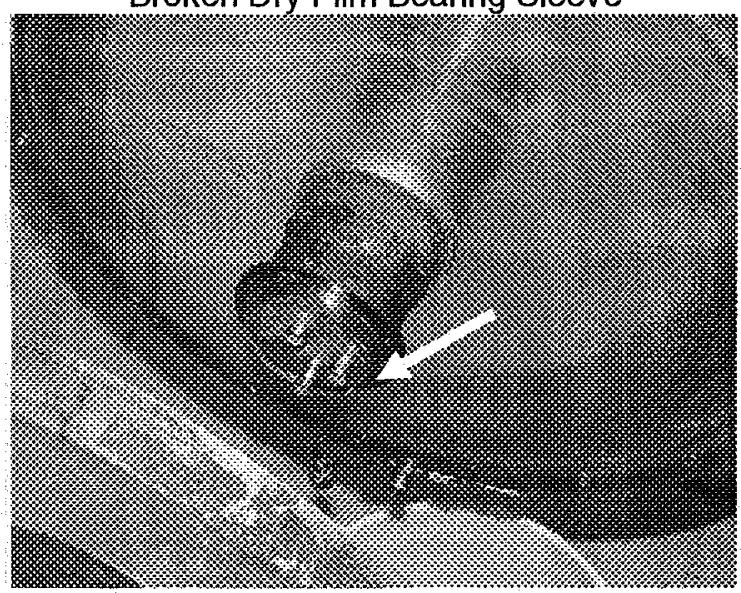

Broken Dry Film Bearing Sleeve

Figure 8. Disassembly Findings from Test Run 3

\section{System Modifications and Hardware Failures}

Several modifications were made to both hardware and software to improve the operation of the VPCAR or to insure the test configuration properly assessed it as a candidate ELS technology. Throughout system checkouts and testing there were various components that failed and were repaired or replaced. Hardware failures did occur to ancillary components that are not related to VPCAR design, but are addressed herein for completeness. Some failures are indicative of design issues and are further addressed as such. Figure 9 shows the final system schematic at the end of testing with all modifications included. 


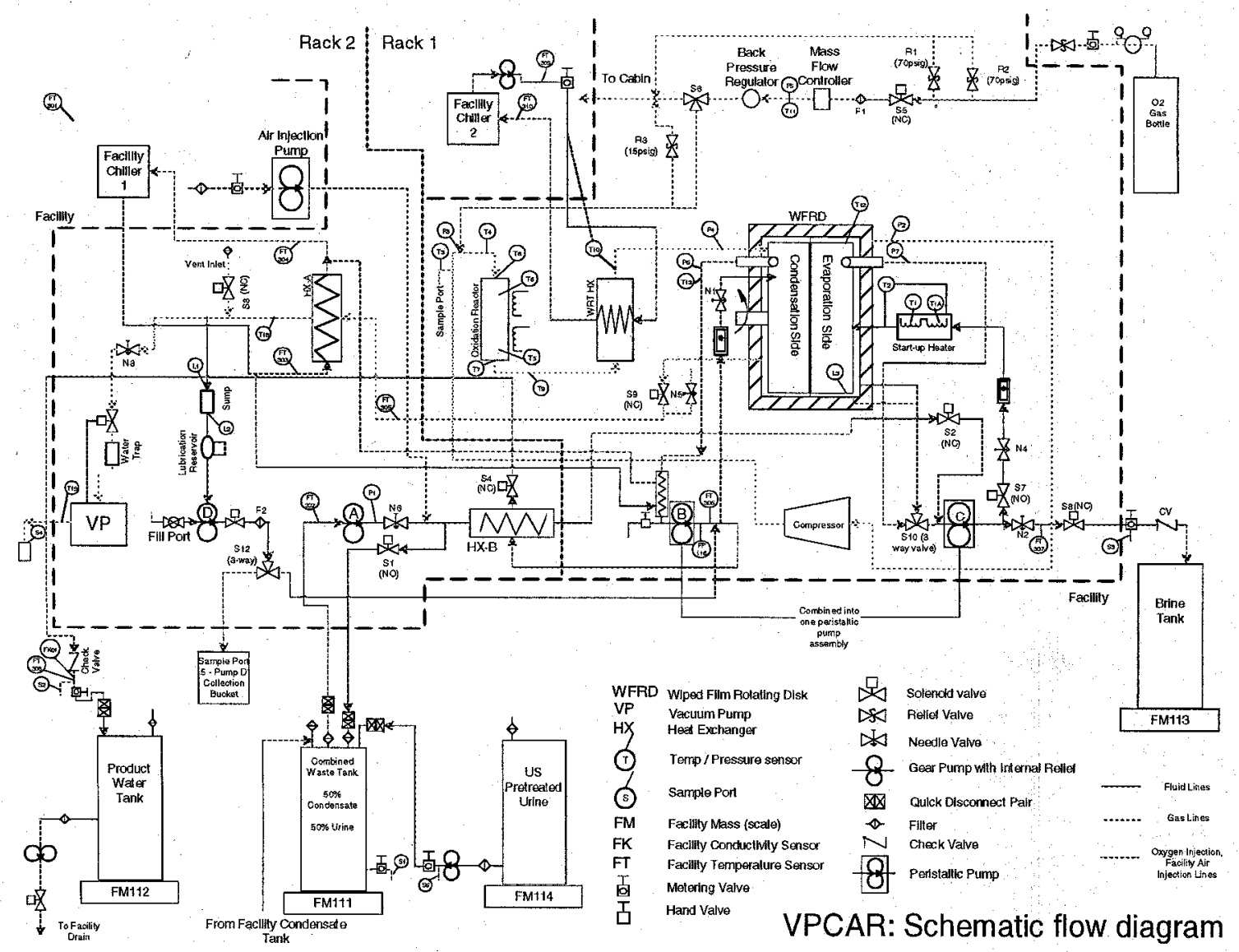

Figure 9. Final Configuration VPCAR Schematic Flow Diagram

System Modifications - WRT HX Coolant Flow - The V1 valve regulating coolant flow through the WRT $H X$ did not function properly when the hardware was received. The coolant is supposed to regulate the fluid temperature just downstream of the WRT HX to $104.4 \mathrm{C}(220 \mathrm{~F})$; however the valve did not open properly to do this. The $V 1$ valve was replaced with a metering hand valve and gear pump that was controlled by facility software to maintain a temperature around $104.4 \mathrm{C}(220 \mathrm{~F})$.

Heat Exchanger $A(H X$ A)- Initially the circulating feed loop, which was cooled to $18.3 \mathrm{C}(65 \mathrm{~F})$, was routed through heat exchanger $A$ to provide cooling for the vapor leaving the condenser. However, the need to cool the feed line proved unnecessary, so the plumbing for HX A was changed to have a facility chiller provide the necessary coolant for the vacuum line. The feed loop was routed to only circulate through the facility storage tank without passing through any other system components first.

Gravity Sump Control - Originally the software caused the gravity sump to empty to the brine tank each time $L 3$, the float valve inside the sump, went high. This did not allow the system to maintain its desired concentration level because of the quantity of brine leaving the system. Software was modified to return the gravity sump into the feed stream instead of dumping to the brine tank. However, if $L 3$ remained high for more than 20 seconds, then it sent the brine in the sump to the brine tank. Also, the float valve that triggered L3 in the gravity sump failed during testing. It was replaced with an identical part and functioned properly for the remainder of the test.

During the inspection of the failed float valve, a significant amount of black particles could be seen inside the bottom of the sump. These were determined to be from the drive belts inside the WFRD. A mesh screen was sealed over the opening of the sump to catch any particles that might get into the system fluid lines and cause other hardware damage.

Air Injection - An air injection pump was added to the feed loop to provide $5 \%$ free gas in the feed to meet requirements for free gas in the waste water. This gas quantity is representative of the quantity observed on the International Space Station and expected during ELS missions. This pump was controlled by facility software and allowed air injection at a rate of $40 \mathrm{ml} / \mathrm{min}$.

System Feed Heater - In order to facilitate evaporation in the WFRD, the feed entering the system passed first through an inline heater to raise the temperature. This was only necessary during the initial operation. After steady state was achieved, the inline heater was manually turned off to prevent overheating and causing a system shutdown. Early in system checkouts at MSFC, this feed heater failed. It was replaced by two $300 \mathrm{~W}$ 
facility heaters installed in series and controlled by facility software to a temperature range of $54.4-65.6 \mathrm{C}$ (130 $150 \mathrm{~F}$ ) based on $\mathrm{T1}$. This prevented any system shutdowns due to the feed heater not being turned off manually.

Feed Line Pressure Transducer - The feed line pressure transducer, which controls when feed is taken into the system, failed during testing. Due to lead times, a new pressure transducer could not be ordered to complete testing, so a facility sensor was used. This one allowed feed pressure to be properly monitored for the remainder of testing.

Solenoid Valves - Three solenoid valves failed (S7, S8, and S10) and were replaced during testing. Replacement valves were similar to the original ones and functioned properly for the remainder of the test.

Bellows Fitting Downstream of WRT HX - Before the start of the second test run, a significant vacuum leak was found in a flexible bellows fitting downstream of the WRT HX before entering the WFRD. Due to time constraints on ordering a new fitting, the leak was sealed with a high temperature RTV sealant and allowed to fully cure. This kept the fitting from leaking for the remainder of testing.

WFRD Housing Feed Tubes - During the first disassembly of the WFRD rotating sumps, two of the three feed tubes attached to the WFRD housing were found to be broken (see Figure 10). This allowed feed to leak into the WFRD housing and cause the gravity sump to be high on a regular basis. The two broken tubes were repaired and the third was reinforced to prevent leakage. After the repair, the gravity sump stayed low almost continuously. However, since the WFRD housing was dryer, any brine that splashed out of the rotating sumps became baked onto the shaft and WFRD components as seen in Figure 11. This is a normal occurrence when there is no feed leaking into the WFRD housing.

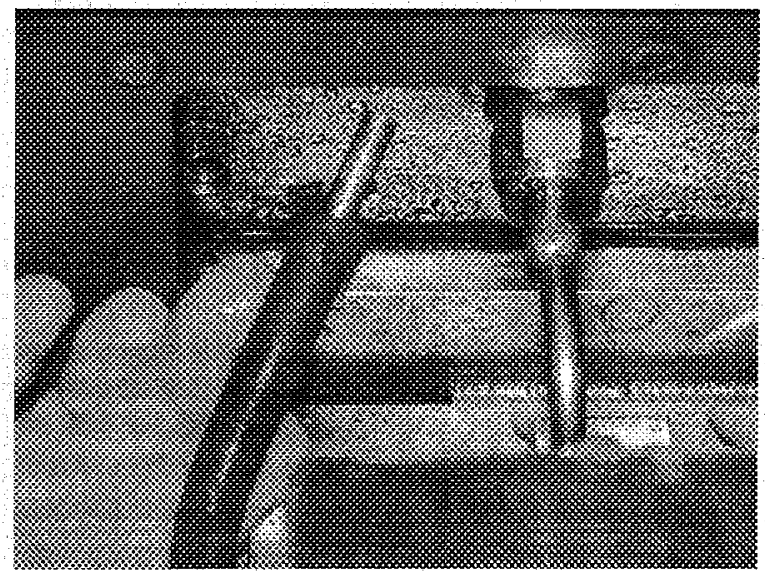

Figure 10. Broken WFRD Housing Feed Tube
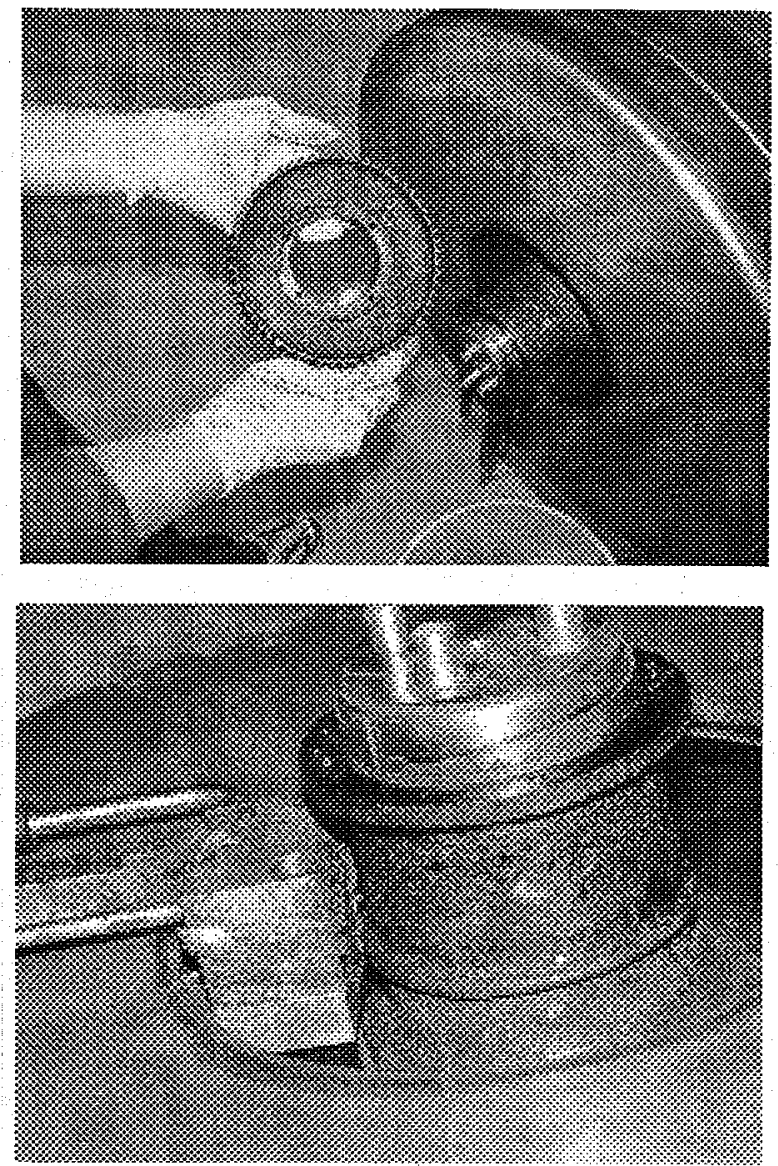

Figure 11. Precipitation in WFRD

Failures Related to Design Issues - Pumps B and C The initial system configuration had pumps $B$ and $C$, product and brine respectively, at an elevation lower than that of the WFRD. This allowed for gravity to assist with moving fluid through the system. Since there is no gravity assistance in a microgravity situation, both pumps were initially elevated to remove this help. However, neither pump was able to overcome the vacuum level of the system and were returned to their original positions.

During initial operation, the system would not produce enough product water to keep a steady flow through the product water pump (pump B). This caused it to run dry and damage the gears. After multiple failures with the gear pump heads for $B$ and $C$, both pumps were removed from the system. Before test run 2, they were replaced with one 4-channel peristaltic pump similar in design to that used by the Urine Processor Assembly. This modification made a significant impact on the operation of the system. During system checkouts and test run 1 , it could take up to 3 hours for any product water to leave the system. Once the peristaltic pump was installed, the system began producing water almost immediately.

A pressure transducer was added to the outlet side of the product lines of the pump to ensure that there was good flow to the product tank. The solenoid valve that allows product water to empty into the facility tank does not stay open continuously until $T 12$ reaches $48.9 \mathrm{C}$ 
$(120 \mathrm{~F})$. As pressure builds inside the product lines from the product water, additional stress is put on the peristaltic tubing. Software was added to cause the product water solenoid valve, $S 4$, to open when the pressure reached 2070 torr ( 40 psia) and allow flow to the tank. The peristaltic pump internal tubing failed during the third test run. This allowed product water to leave the system through the vacuum line, thus increasing the amount of water passing through the vacuum pump. At this point software was modified to cause S4 to open when the pressure reached 1550 torr (30 psia). The tubing was replaced and the pump operated well for the remainder of testing.

Pump D Drain - Because any uncondensed product water left the system through the vacuum line, there was a water collection trap set up just downstream of HX A to prevent any of the fluid from passing through the vacuum pump. Originally, the pump that drained this collection trap, pump D, was sent through the system lubrication line to the product water tank. However, to have an accurate mass balance of how much product water the system was actually making, pump $D$ was rerouted to a facility collection bucket. A three-way solenoid valve was added upstream of the pump to allow software to send any water in the collection trap back into the system lubrication line for the first 15 minutes of operation and then to the facility collection bucket for the duration of operation.

Product Water Line - Once the peristaltic pump was added to the system to replace the brine and product water pumps, it was observed that much of the product water was leaving the WFRD before it had condensed. A facility heat exchanger was added on the product water line upstream of the peristaltic pump inlet to help this vapor condense. When the peristaltic pump was added to the system, clear tubing was used to connect it to the WFRD. The ability of the peristaltic pump to move two phase flow showed that vapor was leaving the condenser, however since there was no clear tubing when the gear pumps were connected it can not be determined if the cause of the vapor leaving the WFRD is due to the ability of the peristaltic pump or the operation of the system.

Vacuum Pump - Due to the nature of the VPCAR operation, the vacuum pump runs continuously. Because of the large flow rate of excess oxygen and other non-condensables in the VPCAR system, a significant amount of product water was pulled through the vacuum line and did not fully collect in the water trap upstream of the pump. Since the scroll vacuum pump is not designed to pump water vapor, this mode of operation eventually degraded the pump performance to the point that it could not pull down the system to an appropriate starting pressure without the help of a facility pump. A new scroll was placed inside the pump and it operated well. However, by the end of the final test run the pump operation had again started to decline.
Water Quality

Due to the duration of the test, limited water quality data was acquired. TOC ranged from 1 to $8 \mathrm{mg} / \mathrm{L}$ in the product water tank (see Figure 12). The only organic identified in the limited analyses was urea at a concentration of $6.7 \mathrm{mg} / \mathrm{L}$ on Day 6 . Urea accounted for all of the measured TOC on this day, though this was the lowest TOC value measured during the test. Given the fact that no alcohols (C1-C4) or acetone were identified in 2 separate product water samples, it is likely that the catalytic reactor was effective at removing these contaminants. Since urea is not very volatile and is relatively easy to oxidize at elevated temperatures, it is very possible that its presence in the product water is indicative of a leak from the evaporator into the condenser. Additional testing will be required to fully assess the organic quality of the product water, though lower TOC levels may be easily achieved with the development of an improved catalyst or a higher reactor temperature. Another possibility is the use of adsorbent media in a polishing bed for the product water to reliably meet $<3 \mathrm{mg} / \mathrm{L}$ in the product water (current NASA specification). The $\mathrm{pH}$ of the product water ranged from 4.4 to 6.7 , while conductivity results ranged from 30 to 83 $\mu \mathrm{mhos} / \mathrm{cm}$. Again, only limited analytical data was available, but the ionic characterization indicates that the vast majority of inorganic constituents were identified. Though some inorganic contaminants may have volatilized and passed through the catalytic reactor, it is expected that the inorganic species were either contamination from the product water plumbing, oxidation by-products from the catalytic reactor, or were present in the product water due to a leak from the evaporator. Table 4 provides a summary of the inorganic data. Phosphate, sulfate, chloride, magnesium, potassium, sodium, and zinc were all present in the product water samples at a concentration approximately 2.5 orders of magnitude reduced from the waste water, supporting the possibility of a leak from the evaporator. Similarly, the only organic contaminant identified in the product water (urea) was also present in the waste water at a concentration approximately 2.5 orders of magnitude greater. Other inorganic contaminants that were present at lower concentrations in the waste water showed a less significant decrease in concentration from the brine to the product water, possibly due to contamination from the product water plumbing. Though leak tests were performed of the system to verify no leaks in the region under vacuum, no leak test was done between the evaporator and condenser. Further investigation of the hardware and seal design would be required to determine if a system leak was the reason for the contamination. If the source of the contamination is primarily from the product water plumbing, improved materials selection may eliminate the contaminants from the product water. Given the uncertainty in the potable water quality due to the limited data set and the potential for leakage from the brine, no conclusions can be made regarding the need for posttreatment of the VPCAR product water. 


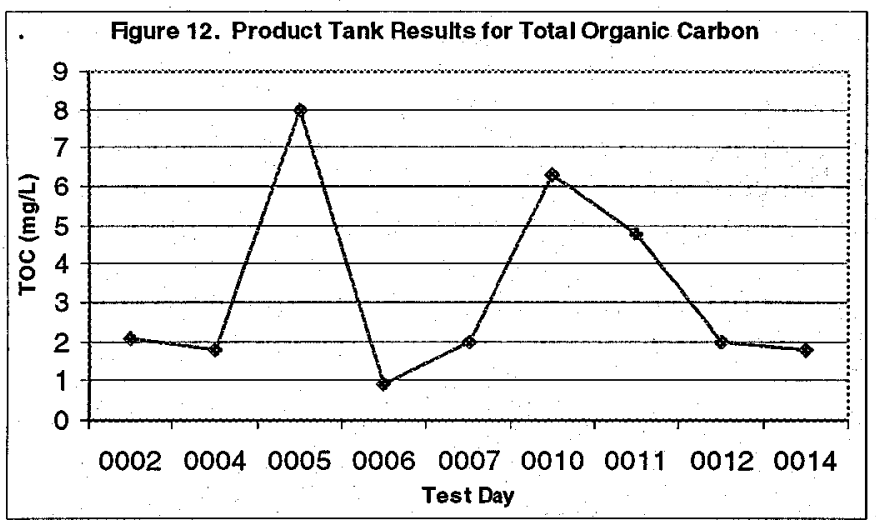

Table 4. Summary of Inorganic Contaminants

\begin{tabular}{|l|r|r|}
\hline & \multicolumn{2}{|c|}{ Concentration (mg/L) } \\
\cline { 2 - 3 } Contaminant & Waste Water & Product Water \\
\hline Chloride $^{*}$ & 1810 & 5.8 \\
Fluoride* $^{*}$ Nitrate $^{*}$ & 4.4 & 0.2 \\
Nitrite $^{*}$ & 23 & 0.4 \\
Phosphate $^{*}$ & 26 & 2 \\
Sulfate $^{*}$ & 510 & 0.6 \\
Ammonium $_{\text {Calcium }}$ & 2860 & 6.5 \\
Magnesium & 136 & 2.7 \\
Potassium & 63.3 & Not detected \\
Sodium & 42.1 & 0.06 \\
Zinc & 1610 & 3.6 \\
Nickel & 1100 & 2.7 \\
Molybdenum & 4.3 & 0.02 \\
Manganese & 0.18 & 0.09 \\
Iron & 0.014 & 0.022 \\
Copper & 0.006 & 0.017 \\
Chromium & 0.23 & 0.29 \\
Aluminum & 0.023 & 0.023 \\
\hline
\end{tabular}

* Average of 4 data points, all other contaminants are from Test Day 6 of Test Run 3

\section{DISCUSSION}

\section{Operational Issues}

One objective of this test was to fully automate VPCAR operations using facility software, including transfer of waste water to the VPCAR waste tank. However, various operational issues presented themselves over the course of testing that required almost continuous monitoring of the hardware to insure operation. The following discussion will address these issues and their potential impact on the continuing development of the VPCAR technology.

\section{System Pressure Transducers}

Several of the system pressure transducers required recalibration on a regular basis. Keeping these transducers calibrated was essential for VPCAR process, including feed intake and system startup. Often times the actual pressure would be approximately 10-12 torr lower than what the data stream was reading, however this amount was significant enough to effect system operation. There were several instances where there would be a system alarm causing a shutdown due to pressure deltas over the acceptable limit when the actual pressures were much lower once the transducers were calibrated. It is recommended that a higher quality pressure transducer be chosen for the VPCAR.

\section{System Vacuum Pump}

As was previously discussed, the system vacuum pump had difficulty maintaining a system pressure low enough for start up. Even after the scroll was replaced in the pump, it still had operational problems. In order to start up the system, either a facility vacuum pump was required or the compressor had to be operated in manual mode to help the system pump to achieve the startup pressure which is based on the vapor curve for T12. By alleviating the amount of product water that leaves the system through the vacuum line, the life of the vacuum pump would be extended and could prevent the need to assist it at startup.

\section{System Feed Intake Control Logic}

Feed intake is based on the pressure difference between P7 and P2 (the pressure of feed entering the WFRD and vapor exiting the WFRD to the compressor respectively). A feed intake setpoint is manually entered into the software and then the control logic pulls in feed based on the P7-P2 pressure delta. However, during early operation the system requires a greater amount of feed intake until it reaches a temperature and pressure supporting a consistent production rate. Once the production rate increases, the P7-P2 delta greatly decreases and can pull in too much feed if the setpoint is not lowered. In order to alleviate the need of constant monitoring, facility software was used to control the setpoint based on temperature. However, there were still times the setpoint had to be manually monitored. If there was low production rate, less feed would be required and the setpoint would need to be adjusted to prevent flooding inside the WFRD. Once production rate increased again more feed was needed or it would run dry. Thus, the setpoint had to be adjusted based on current system operation.

\section{Compressor Temperatures}

When the hardware was received, there were 5 thermocouples placed on the body of the compressor that were not read into the data stream. Before the third test run these thermocouples were set to be monitored continuously by facility software. Multiple system shutdowns were observed due to one of the compressor thermocouples exceeding the temperature setpoint. To cool the compressor, a facility fan was used to provide a continuous air flow over the compressor. 


\section{Rotating Sump Lubrication}

The rotating sumps inside the WFRD rotate about a fixed shaft with a dry film bearing sleeve. A lubrication line is set up to provide liquid lubrication to this bearing from the product water line. If the needle valve controlling flow into the lubrication line was closed too much, it would run dry and a loud rubbing noise could be heard from inside the WFRD. However, opening the needle valve too far to insure adequate flow to the shaft would cause product water to almost completely stop flowing into the product tank. This was because the WFRD vacuum pump pulled so much product water into the vacuum line. It was observed that a significant amount of product water would go to the pump $D$ collection bucket when this happened. Maintaining the needle valve for the lubrication flow at the right setting required constant adjustment to prevent either of these situations from occurring. It is recommended that a different lubrication method be set up for the shaft bearing.

\section{Design Issues}

Based on the testing at MSFC and a design assessment by MSFC, ARC, and JSC engineering, the following issues have been identified that must be addressed before further testing of the VPCAR is warranted.

First, the microgravity sump designed for this version of the VPCAR had only limited success. The sump rotates with the evaporator drum, but provides a radial gap of approximately $5 \mathrm{~cm}$ from the center shaft for vapor flow. During each startup and shutdown transition, splashing occurred that resulted in brine escaping the sump through the radial gap. A design modification must be made to prevent brine leakage, with potential concepts being a demister or dynamic seal.

Efforts to achieve $98 \%$ recovery during this test were unsuccessful. Precipitation during Test Run 2 resulted in damage to the pitot tubes. Precipitation continued during Test Run 3, as evident by the increase in brine solids during the test. Though the wipers appeared to control precipitation on the surface of the evaporator, precipitation continued to occur in the microgravity sump, and was also observed in the brine dumped to the brine tank. Given the existing hardware design, 98\% recovery is not viable. This level of recovery is near or beyond the solubility limit for some inorganics in the brine, thus precipitation is inevitable. Several issues contribute to the precipitation, including concentration gradients in the microgravity sump due to its centrifugal force, inherent variability in the feed solids, and controlling the solids concentration in the small volume in the brine loop. These issues have limited other phase change processes to a maximum of $94 \%$ recovery, and will limit VPCAR as well pending additional design modifications.

The VPCAR requires a vacuum with significant capacity to maintain a vacuum on the system while also adding oxygen at a rate of $0.5-1 \mathrm{liter} / \mathrm{min}$. This large volumetric flow rate of gas in the vacuum line also includes a significant quantity of water vapor that is not removed in the condenser. During the test, approximately $1 / 3$ of the total product water was collected as condensate from the vacuum line, instead of in the condenser. Though the vacuum flow rate may be reduced by reducing the oxygen required in the catalytic reactor, ultimately a condensing heat exchanger and gas/water separator will be required upstream of the vacuum pump.

The gear pumps did not meet their performance requirements during the test. Gear pumps are unable to develop the necessary positive suction pressure to overcome the vacuum in the WFRD. Peristaltic pumps worked in this application during the test, and will most likely be required in the flight application. Though peristaltic pumps work well in vacuum applications, the disadvantage is a limited life due to the peristaltic tubing.

The VPCAR requires a significant quantity of gaseous oxygen for the catalytic reactor operation. Though a more active catalyst may reduce the oxygen requirement, the ultimate oxygen requirement will still exceed oxygen availability during a manned mission. VPCAR would require a direct interface with the Oxygen Generation System, which would require an intermediate tank and compressor.

The VPCAR requires significantly higher power consumption ( $3 \mathrm{KW})$ than other phase change processes. For example, the time-averaged power consumption for the ISS Water Recovery System is approximately $560 \mathrm{~W}$, and the VCD specifically requires only $490 \mathrm{~W}$ while producing approximately $4 \mathrm{lb} / \mathrm{hr}$ of distillate. Besides the impact to the overall power availability for the mission, the additional power consumption places a significant burden on thermal management processes, including the coolant system and the habitat's temperature control system. This issue will limit the applicability of the VPCAR for missions with power and thermal constraints.

Also, the VPCAR must address acoustics to be considered a viable candidate for the Exploration Water Recovery System. Though no specific acoustic measurements were taken during the test, the noise levels are obviously significantly above the existing NASA standards of NC-40. The mechanical design of the VPCAR will require modifications specifically to address the acoustics, and most likely additional noise abatement measures will also be required external to the system to meet acoustics requirements.

Finally, the VPCAR has specific mechanical issues that must also be resolved. The compressor and motor shaft employ oil-based lubrication, which is not viable for the flight hardware. The motor-driven shaft that fractured twice during the test must be redesigned to provide a more stable mechanism for shaft operation. 


\section{CONCLUSIONS}

The specific objectives for this test could not be accomplished due to the various hardware failures encountered during operation. In spite of this limitation, however, significant findings were achieved that provide critical insight into the current state of the VPCAR technology and a direction for future improvements. First, this test showed that the current design of the VPCAR cannot achieve $98 \%$ recovery. Though the VPCAR WFRD design provides the potential to exceed the water recovery of other phase change technologies, at this point additional design improvements and subsequent testing must be performed to quantify the VPCAR advantage. Second, the VPCAR system tested at MSFC must address the various design issues specified herein before proceeding with additional testing to justify a Technology Readiness Level (TRL) of 4 . Finally, the VPCAR control scheme needs to be evolved to better control the VPCAR process. The VPCAR process is a combination of interdependent unit operations that must be optimized for the system to achieve maximum performance. This can only be accomplished by further testing to more fully understand the thermodynamic processes in the VPCAR and how to best control them through the startup and nominal operations.

In spite of these issues, the VPCAR continues to possess advantageous design features. Vapor phase oxidation is a more efficient method for removal of organics than aqueous phase, though the resulting oxygen and power consumption must be fully assessed to determine the viability of this technology for exploration missions. Furthermore, the wiper feature has the potential to improve water recovery by reducing precipitation effects on the evaporator surface, assuming the incorporation of design and/or operational modifications prevent precipitation in other regions of the brine loop from impacting system performance. Ultimately, further development of this technology will be required to advance it to the point that it is a viable candidate for exploration missions

\section{REFERENCES}

[1] Flynn, M. T., M. Tleimat, G. Quinn, T. Nalette," Performance Testing of the Vapor Phase Catalytic Ammonia Removal Engineering Development Unit", SAE Technical Papers Series No. 2005-01-3033, presented at the $35^{\text {th }}$ International Conference on Environmental Systems, Rome, Italy, July 11-14, 2005.

\section{CONTACT}

Layne Carter

NASA Marshall Space Flight Center

El12

2565447082

lavme.carter@nasa.gov 